\title{
Call for Papers: General Issue
}

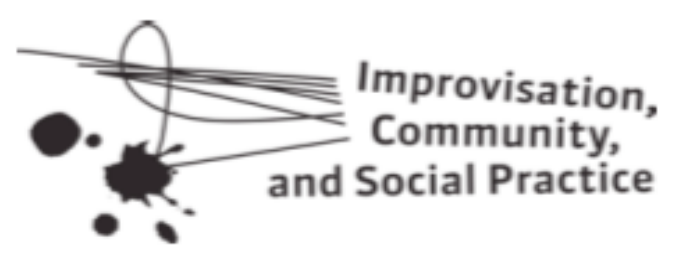

We are accepting submissions on an ongoing basis for our general issues.

Critical Studies in Improvisation/Études critiques en improvisation is an open-access, peer-reviewed, electronic, academic journal on improvisation, community, and social practice housed at the University of Guelph. The editorial and advisory boards are made up of leading international scholars spanning diverse disciplines.

While improvisational music has historically been analyzed within specific musical disciplines, what distinguishes the research profiled in CSI/ÉCl is its emphasis on improvisation as a site for the analysis of social practice. We contend that improvisation demands shared responsibility for participation in community, an ability to negotiate differences, and a willingness to accept the challenges of risk and contingency. Yet improvisation is a contested term. Its cultural significance is in dispute both in the academy and in the eyes of the general public. CSI/ÉCl seeks to reveal the complex structures of improvisational practices and to develop an enriched understanding of the social, political, and cultural functions those practices play.

We are particularly interested in historically and contextually specific articles that interrogate improvisation as a social and musical practice, and that assess how innovative performance practices play a role in developing new, socially responsive forms of community building across national, cultural, and artistic boundaries.

CSI/ÉCI publishes twice a year, in May and December. We accept submissions of papers, interviews, and book reviews on an ongoing basis throughout the year. Authors should carefully review the Online Submission and Author Guidelines before submitting their work. 